\title{
Influência de requisitos NCAP e do programa Rota 2030 na implementação de sistemas AEB para indústria automotiva brasileira.
}

\author{
Deocarlo Guinzani ${ }^{1}$, Emerson Batagini ${ }^{2}$, Guilherme Alves Lima ${ }^{3}$ e Pedro Santos ${ }^{4}$ \\ ${ }^{1}$ Robert Bosch Ltda \\ E-mails: external.Deocarlo.Guinzani@br.bosch.com,Emerson.Batagini@br.bosch.com, \\ external.Guilherme.Lima2@br.bosch.com, external.Pedro.Santos3@br.bosch.com
}

\section{RESUMO}

A adoção de sistemas de assistência de direção está cada vez mais relacionada com o aumento da segurança nas estradas. Em alguns países da Europa e nos Estados Unidos já existem ou estão sendo desenvolvidas legislações relacionadas à implementação de novas tecnologias de segurança veicular, como o AEB - frenagem automática de emergência. No Brasil existem três pilares que visam trazer esses tipos de sistemas para o cenário nacional, são eles: o roadmap do DENATRAN, que visa estabelecer, como legislação, o uso de novas tecnologias para segurança veicular; o NCAP, que estabelece requisitos para classificação de veículos em níveis de segurança; e o Rota 2030 que busca antecipar a aplicação desses sistemas através de incentivos fiscais. $\mathrm{O}$ artigo visa estudar como o AEB, uma das tecnologias recomendadas por esses três pilares, pode reduzir o índice de acidentes no cenário nacional com base no cenário mundial.

\section{INTRODUÇÃO}

Segundo a OMS (Organização Mundial da Saúde), no ano de 2018 acidentes de trânsito foram a oitava maior causa de morte de mundo, com 1,35 milhões de vítimas pelo globo. Dado esse cenário faz sentido o desenvolvimento de ações, tecnologias e infraestrutura que diminuam esse índice. No que tange ao setor automotivo, novos sistemas de segurança veicular estão sendo desenvolvidos e visam impedir os acidentes ou pelo menos mitigar seus danos, através de alertas ao condutor, atuação autônoma do sistema de freio ou pós acidente, proteção via Airbags.

O ABS (do inglês Anti-lock Brake System) é um dos primeiros equipamentos criados para aumentar a segurança veicular em frenagens de emergência ou em situações em que o atrito entre a roda e o piso é menor. Ele modula a pressão do fluído de freio quando detecta uma velocidade maior do veículo que da roda, impedindo seu travamento.

Esse sistema já possui uma evolução, o ESC (do inglês Electronic Stability Control - Controle de estabilidade eletrônico), que além de realizar a modulação da pressão do fluído de freio, também implementa funções de controle de tração (TCS -Traction Control System) e de dinâmica (VDC - Vehicle Dynamics Control) do veículo. Utilizando os sensores do ABS, e alguns adicionais, como um acelerômetro, ele possui válvulas que podem direcionar a pressão do fluido de freio para cada uma das rodas independentemente. Dessa forma, ele pode evitar 
que as rodas derrapem durante a aceleração do veículo (TCS), possibilita o desvio abrupto de um obstáculo inesperado na pista sem que o carro derrape (VDC).

Atualmente, novos componentes de assistência ao condutor estão sendo inseridos no sistema de freio, e são co-responsáveis pela segurança veicular. Esses sistemas vêm em forma de radares, câmeras e sensores ultrassom, e detectam objetos ao redor do veículo, e podem avisar o motorista em caso de colisão eminente ou proximidade, ou até enviar sinais de desacelaração para o ESC, que realiza a atuação automática da frenagem. Câmeras e radares trabalham como um sistema redundante na detecção de objetos do veículo, aumentando ainda mais a segurança e confiabilidade, principalmente na execucação de funções de frenagem automática, como o AEB, do inglês Automatic Emergency Braking e ACC (Adaptative Cruise Control).

Nesse sentido, o Brasil tem buscado adotar essas novas tecnologias para aumentar a segurança veicular. Somente em 2018, acidentes de trânsito foram responsáveis por mais de 40 mil mortes. Nesse mesmo ano, o governo sancionou o Programa Rota 2030, que compila diversas ações e incentivos para montadoras que produzirem carros mais seguros. Ele começa a beneficiar montadoras que incluam itens de segurança veicular nos novos modelos. O DENATRAN, por sua vez, estabeleceu um roadmap para implementação destes componentes.

Por fim, tem-se também algumas possíveis mudanças no Latin NCAP, entidade responsável por pontuar veículos de acordo com o nível de segurança, que podem incluir o AEB como critério na avaliação.

O objetivo desse artigo é analisar a motivação da implementação dessas novas tecnologias no Brasil, comparando o cenário brasileiro com outros países que já possuem legislações que cobrem essas aplicações, além de expor os equipamentos necessários para o uso de funções como o AEB, e como o mercado pode reagir, baseando-se nos dados de outros países também.

\section{LEGISLAÇÕES E PROGRAMAS}

\subsection{Rota 2030}

No Brasil um dos principais programas de incentivo à tecnologias automotivas é o programa Rota 2030 - Mobilidade e Logística, que tem como objetivo apoiar o desenvolvimento tecnológico, a competitividade, a inovação, a segurança veicular, a proteção ao meio ambiente, a eficiência energética e a qualidade de automóveis, de caminhões, de ônibus, de chassis com motor e de autopeças. As principais diretrizes do programa são: aumento dos investimentos em pesquisa, desenvolvimento e inovação no país; estímulo à produção de novas tecnologias e inovações de acordo com as tendências tecnológicas globais; promoção do uso de biocombustíveis e de formas alternativas de propulsão e valorização da matriz energética brasileira e incremento da eficiência energética, do desempenho estrutural e da disponibilidade de tecnologias de assistência à direção dos veículos comercializados no País [1].

Para aderirem ao programa as montadoras automotivas devem obedecer diversos requisitos mínimos, e nesse artigo tratar-se-á apenas dos relevantes para futuras análises. Assim, o programa exige que as indústrias do segmento automotivo tenham projeto de desenvolvimento e produção tecnológica aprovado para a produção, no país, de novos produtos ou de novos modelos de produtos já existentes, ou de novas soluções 
estratégicas para a mobilidade e logística, conforme regulamento do Poder Executivo federal. O programa ainda incentiva energia de propulsão limpa e renovável, compreendendo empresas que tenham projeto de investimento relativo à instalação, no país, de linha de produção de veículos com tecnologias de propulsão alternativas à combustão. Adere também empresas que tenham projeto de investimento relativo à instalação de fábrica de veículos leves com capacidade produtiva anual de até 35.000 (trinta e cinco mil) unidades e com investimento específico de, no mínimo, R\$ 23.300,00 (vinte e três mil e trezentos reais) por veículo [1].

Existe uma seção no documento publicado referente ao programa que diz respeito aos requisitos para a habilitação do programa. Basicamente são requisitos legais que as empresas devem possuir para participarem do programa, como por exemplo, a empresa deverá estar regular com a tributação dos impostos. Em relação a esta seção, os parágrafos que merecem mais destaque para serem elucidados em relação a este artigo são os referentes ao incentivo a pesquisa com outras entidades. O programa exige que as empresas tenham parcerias com Instituições Científica, Tecnológica e de Inovação (ICTs). Isso traz oportunidades para o setor acadêmico, uma vez que proporciona troca de conhecimento entre indústria e universidades. Estas podem contribuir com o conhecimento científico, desenvolvendo e buscando novas soluções tecnológicas e as indústrias podem contribuir com a experiência, know-how e verba para financiar e subsidiar as ICTs. Isso também inclui entidades brasileiras de ensino, oficiais ou reconhecidas pelo poder público, permitindo que a difusão da tecnologia não fique restrita somente nos grandes centros acadêmicos, e poderá ser difundida mais facilmente entre a comunidade como um todo [1].

Apesar de todas as exigências que o programa requer para as empresas, é necessário, em contrapartida, ter uma moeda de troca para que as empresas participem ativamente do programa e assim obter o resultado desejado pelo mesmo. Essencialmente esses incentivos são fiscais/financeiros, atuando, como por exemplo, na forma da tributação das empresas participantes do programa. $\mathrm{O}$ artigo 11 diz que a pessoa jurídica habilitada no Programa Rota 2030 poderá deduzir do Imposto sobre a Renda das Pessoas Jurídicas (IRPJ) e da Contribuição Social sobre o Lucro Líquido (CSLL) devidos o valor correspondente à aplicação da alíquota e adicional do IRPJ e da alíquota da CSLL sobre até 30\% (trinta por cento) dos dispêndios realizados no País, no próprio período de apuração, desde que sejam classificáveis como despesas operacionais pela legislação do IRPJ e aplicados conforme as disposições do programa [1].

A seção $\mathrm{V}$ diz a respeito as entidades governamentais responsáveis por acompanhar o programa durante o seu funcionamento, para realizar a manutenção do mesmo. Estas entidades são componentes dos Ministérios da Fazenda, Ministério da Indústria, Comércio Exterior e Serviços e do Ministério da Ciência e Tecnologia, Inovações e Comunicações [1].

A seção VI trata das sanções administrativas que serão impostas as empresas que não cumprirem os requisitos legais exigidos pelo programa. Basicamente existem 3 sanções: a primeira aborda sobre o cancelamento da habilitação com efeitos retroativos; a segunda trata da suspensão da habilitação e a terceira diz respeito da multa de até $2 \%$ (dois por cento) sobre o faturamento apurado no mês anterior à prática da infração [1]. 
Essencialmente, o Programa Rota 2030 será implementado em três fases, durando 5 anos cada uma: a primeira é de 2018 a 2022, a segunda é de 2023 a 2027 e a terceira é de 2028 a 2032; durando um total de 15 anos de implementação [2].

\subsection{GLOBAL NCAP}

O Global NCAP é um programa de avaliação de novos carros, que pertence à Towards Zero Foundation, uma instituição que não possui fins lucrativos. Assim, como as outras derivações da NCAP, a Global tem como objetivo central promover a adoção universal dos mais importantes requisitos de segurança padronizados das Nações Unidas e possui algumas visões interessantes, entre as quais pode-se destacar: uma aspiração de um mundo livre de acidentes e danos sérios; em torno de 2020 objetiva-se que todos os novos carros produzidos estejam suportando os requisitos de segurança modelados pelas Nações Unidas.

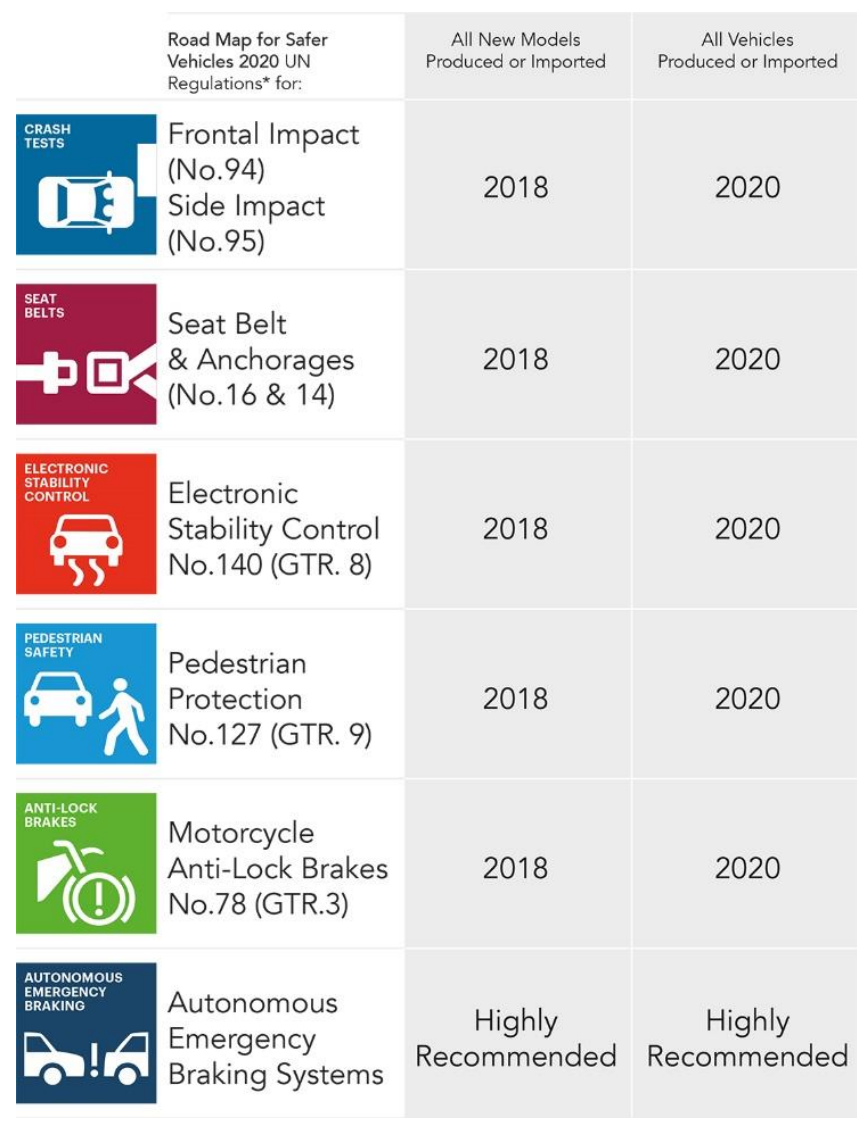

Figura 1 - Roadmap da ONU. Fonte [26].

A Global NCAP adotou também a Road Map for Safer Vehicles 2020 (Figura 1), um documento que contém medidas para prevenção de acidentes de trânsito baseado nas resoluções da ONU (Organização das Nações Unidas). As medidas da ONU são referentes aos impactos frontal e lateral; cintos de segurança e ancoragem, controle eletrônico de estabilidade (ESC); proteção ao pedestre; freios ABS em motocicletas e sistemas de frenagem de emergência autônoma. A Global NCAP unifica todas as 
entidades no grupo que também são voltadas para avaliação dos veículos, porém, existindo cada uma específica para uma região.

\subsection{EURO NCAP}

A EURO NCAP é a entidade responsável por realizar as avaliações nos veículos de toda a Europa. Foi responsável por criar o sistema de avaliação de 5 estrelas que auxiliam os consumidores a comparar o nível de segurança veicular dos automóveis durante o processo de aquisição. Na tabela 1, tem-se o sistema de avaliação desenvolvido pela EURO NCAP [3].

Tabela 1 - Pontuação NCAP.

\begin{tabular}{|c|c|}
\hline ESTRELAS & DESCRIÇÃOO \\
\hline 5 & $\begin{array}{l}\text { Bom desempenho em proteção de acidentes no geral. Bem equipado } \\
\text { com robusta tecnologia para evitar acidentes. }\end{array}$ \\
\hline 4 & $\begin{array}{l}\text { Bom desempenho em proteção de acidentes no geral, pode ser } \\
\text { apresentada tecnologia adicional para evitar acidentes }\end{array}$ \\
\hline 3 & $\begin{array}{c}\text { Média a boa proteção de ocupante mas falta tecnologia para evitar } \\
\text { acidentes. }\end{array}$ \\
\hline 2 & $\begin{array}{c}\text { Proteção de acidente nominal, mas falta tecnologia para evitar } \\
\text { acidentes. }\end{array}$ \\
\hline 1 & Proteção de acidente marginal. \\
\hline
\end{tabular}

O número de estrelas reflete o quão bom é o desempenho do veículo nos testes, mas também é influenciado por qual equipamento de segurança está instalado no carro. Isso significa que um alto número de estrelas não mostra somente que a avaliação foi positiva, mas que também o veículo possui algum ou vários dispositivos de segurança veicular. A avaliação em estrelas vai além dos requisitos legais mínimos, e nem todos os novos veículos precisam se submeter aos testes. Em contrapartida, se um veículo atender apenas os requisitos mínimos legais de acordo com a legislação de cada país, este por usa vez não atingirá nenhuma estrela. Porém, quando um carro recebe baixa avaliação, isso não significa que ele não seja seguro, apenas significa que é menos seguro do que os seus concorrentes [3].

A EURO NCAP recomenda sempre observar a última avaliação realizada por eles, sendo esta sempre a mais significativa em relação as anteriores. Ainda, a versão europeia da NCAP possui desde 2016 um sistema duplicado de novas avaliações. Fundamentalmente esse sistema é para avaliar a segurança de veículos standard e veículos da mesma linha que tenham "add-ons", ou seja, dispositivos opcionais para a segurança do mesmo. Por exemplo, a versão standard do veículo x tem ABS e a versão x.1 tem ESC, a partir disso o veículo passa a ter duas avaliações [3].

É impossível para a EURO NCAP avaliar todos os novos carros lançados, dado o alto volume de produção. Essencialmente os critérios de escolha são os "best-sellers", os populares pela região europeia e os que são importantes em algum segmento específico do mercado [4]. 


\subsection{LEGISLAÇÃO GLOBAL - NAÇÕES UNIDAS}

As Nações Unidas possuem metas ambiciosas para a segurança no trânsito, entre as quais pode-se destacar a redução pela metade das mortes e lesões no trânsito até 2020 e oferecer acesso a sistemas de transporte seguros, acessíveis e sustentáveis para todos até 2030.

O Enfoque Seguro, é um documento, baseado no Visão zero (a ser abordado posterioromente), criado pela ONU e tem como objetivo informar e orientar a construção de um sistema de trânsito seguro para prevenir acidentes e, caso estes ocorram, assegurar que as forças do impacto não resultem em lesões graves nem em morte, e que as pessoas que sofrerem lesões sejam resgatadas e recebam atendimento traumatológico adequado [5].

Basicamente o sistema serve para tomar ações de maneira holística diante da prevenção de acidentes de trânsito, promovendo assim um nível de segurança elevado a todos os envolvidos no sistema.

Segundo a ONU, existem quatro princípios orientadores básicos e centrais em um sistema seguro: 1) As pessoas cometem erros que podem levar a acidentes de trânsito, 2) o corpo humano tem uma capacidade física conhecida e limitada para tolerar as forças dos impactos antes de ocorrerem danos, 3) as pessoas são responsáveis por procederem com atenção e conforme as leis de trânsito, 4) mas existe uma responsabilidade comum entre os que projetam, constroem, administram e usam vias e veículos para prevenir acidentes que resultem em lesões graves ou morte e prestar atendimento após um acidente e para multiplicar seus efeitos, todas as partes do sistema devem ser fortalecidas em combinação, de modo que os usuários das vias ainda estejam protegidos se uma parte falhar [5].

Em 2010, a assembleia das Nações Unidas aprovou a Resolução 64/255 que estabelece a Década de Ação pela Segurança no Trânsito para o período de 2011-2020 com o intuito de estabilizar e reduzir os níveis previstos de mortes por acidente no mundo inteiro. Originalmente são cinco pilares: gestão da segurança no trânsito; vias e mobilidade mais seguras; veículos mais seguros; usuários das vias mais seguros e resposta pós-acidente.

Pode-se perceber que o terceiro pilar - veículos mais seguros - está intimamente relacionado com todo tipo de tecnologia que aumente a segurança veicular, sejam dispositivos de frenagem, airbags adicionais ou até mesmo sistemas de frenagem autônoma como o AEB. Ou seja, as Nações Unidas possuem grande influência na adesão dessas novas tecnologias na frota de seus países membros.

\subsection{LEGISLAÇÃO GLOBAL - VISÃO ZERO}

O Vision Zero é uma estratégia para eliminar todas as fatalidades no trânsito e lesões graves, ao mesmo tempo em que aumenta a mobilidade segura, saudável e equitativa para todos. Originado na Suécia na década de 90, o Vision Zero mostrou ser bem- 
sucedido em toda a Europa e agora está ganhando força nas principais cidades americanas [6].

O programa possui um olhar diferente que quebra os paradigmas da segurança veicular. Ele considera que as mortes de trânsito são evitáveis, e integra a falha humana nessa abordagem; Busca a prevenção de acidentes fatais e severos com o tratamento sistêmico de que salvar vidas não é caro. Graças ao programa nenhuma criança morre envolvendo acidentes de bicicleta desde 2008 na Suécia [7].

Outros lugares começaram a adotar os princípios utilizados no programa, como por exemplo Nova Iorque. Atualmente, na cidade, cerca de 4.000 cidadãos são feridos e mais de 250 são mortos por ano. Ficar preso em um veículo é a causa principal de mortes por crianças abaixo de 14 anos. A cada duas horas um nova-iorquino é morto ou ferido [8].

A próxima seção apresentará dados sobre acidentes no Brasil e no mundo, buscando mapear a criticidade dos acidentes de trânsito e apontar semelhanças e diferenças entre entre os cenários brasileiro, europeu e americano, a fim de avaliar a aplicabilidade de legislações ou medidas adotadas em outras países, no Brasil, além de de entender a motivação de tantos programas e roadmaps que visam mitigar os danos ou inclusive evitá-los, em acidentes de trânsito.

\section{2. ÍNDICES DE ACIDENTES NO BRASIL E NO MUNDO}

No ano de 2011 foram registrados 188.925 acidentes de trânsito no Brasil, sendo 3,71\% deles com mortos e $33,86 \%$ com feridos. Acidentes de colisão traseira representaram $29,11 \%$ de todos os acidentes e se configurou como o tipo de acidente com maior número na maioria dos estados. Em Mato Grosso, Mato Grosso do Sul, Amazonas, Amapá e Tocantins, colisão traseira perde para acidentes de saída de pista [9].

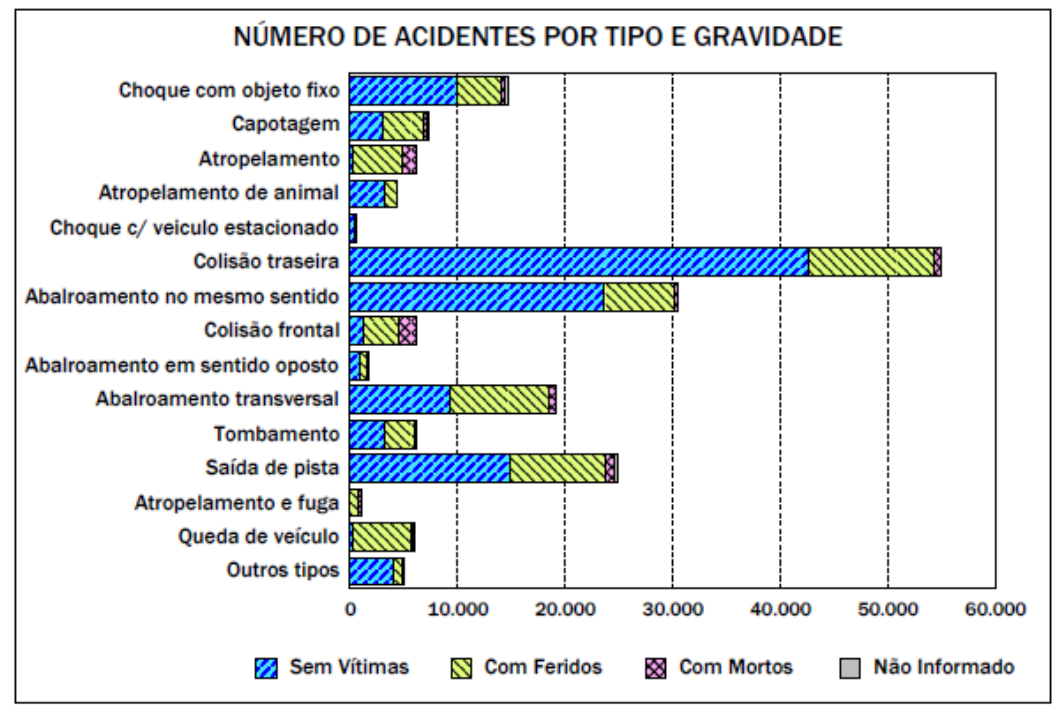

Figura 2 - Ocorrência dos tipos de acidentes no Brasil. Fonte [9].

A Figura 2 mostra uma representação gráfica do número de acidentes por tipo e gravidade no Brasil em 2011 e foi obtida através de dados do DNIT (Departamento Nacional de Infraestrutura de Transportes), baseados nos registros efetuados pelo Departamento de Polícia Rodoviária 
Federal - DPRF. Nela é possível verificar que colisão traseira foi a maior causa de acidentes no Brasil nesse ano, seguida por abalroamento no mesmo sentido e saída de pista.

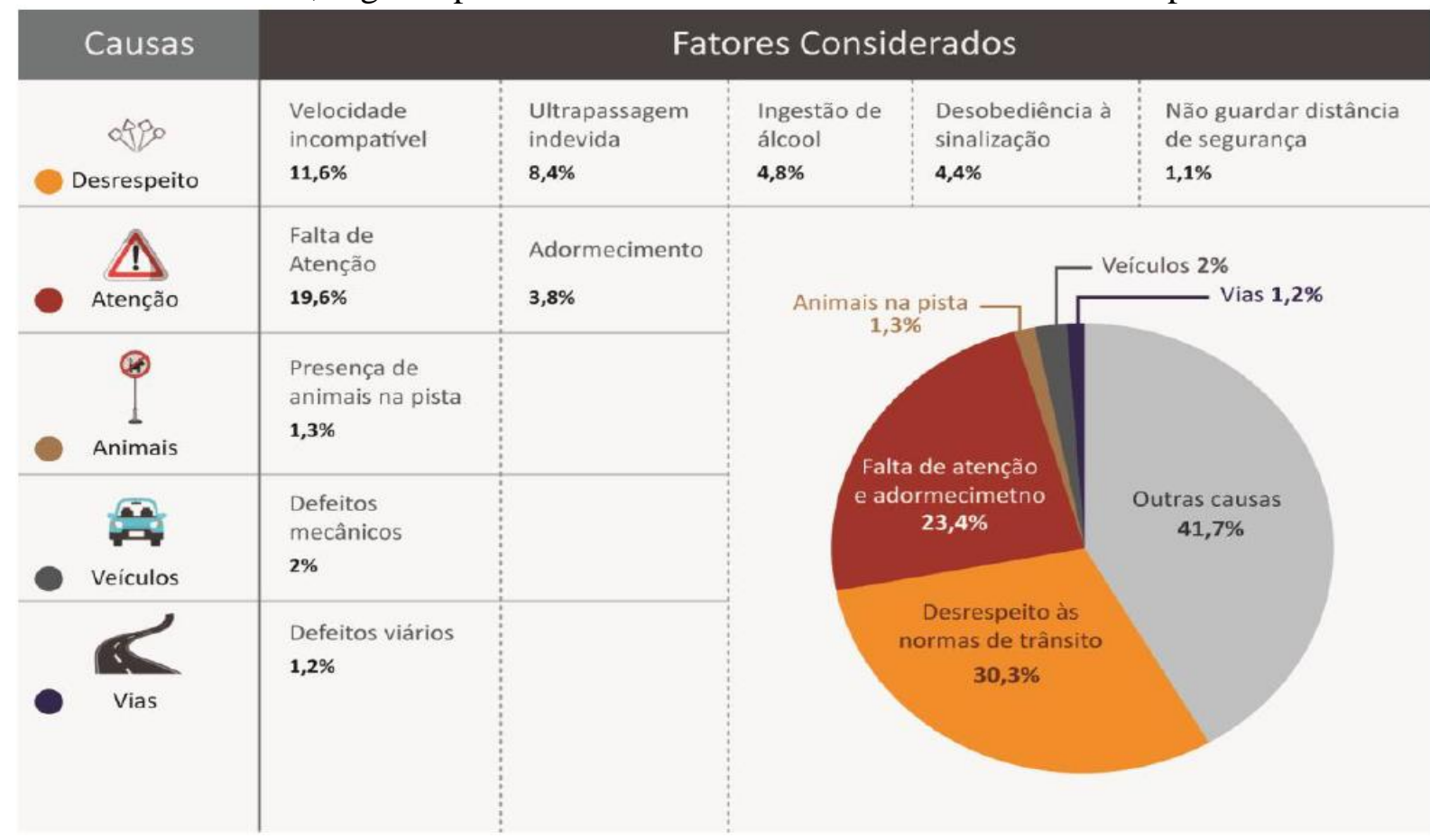

Figura 3 - Total de mortes nas rodovias federais por tipo de causa do acidente (2007-2016), em $\%$. Fonte [10].

Além disso, um estudo do Ministério dos Trasnportes, Portos e Aviação Civil [10] indica que cerca de 50\% dos acidentes que acontecem no Brasil são devido à falhas humanas, sendo que $30,3 \%$ são devido ao desrespeito às normas de trânsito, $23,4 \%$ são devido à falta de atenção e adormecimento. Defeitos mecânicos, animais nas pistas e condições das vias somam 4,5\% dos acidentes. Outras causas correspondem a 41,7\%. Sendo assim, com dados da PRF (Policia Rodoviária Federal) de 2017 o estudo montou a imagem da Figura 3 . Nela é possível ver que o desrespeito se divide ainda em diversas infrações sendo velocidade incompatível o maior causador de acidentes dessa categoria.

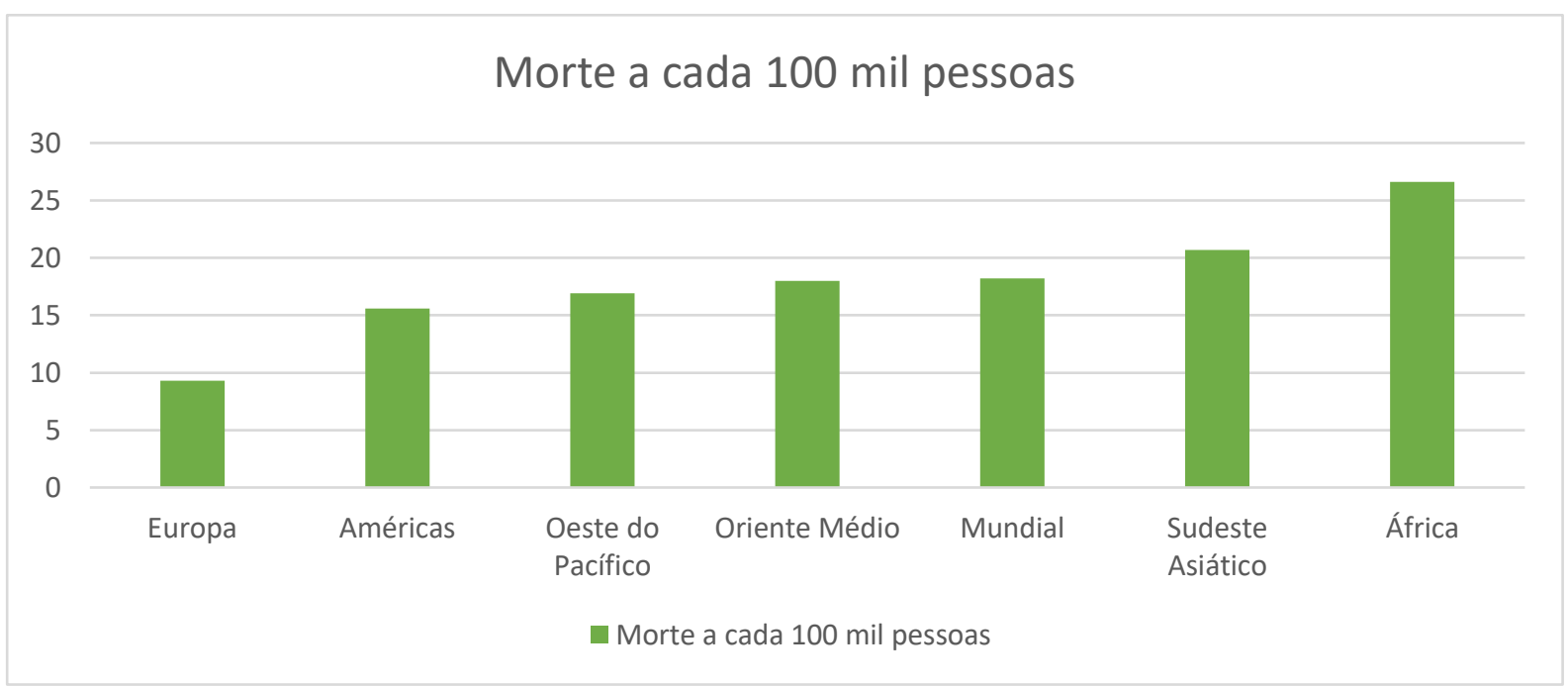

Figura 4 - Morte a cada 100 mil habitantes nas regiões da OMS. Fonte [11]. 
No ano de 2018, a OMS (Organização Mundial da Saúde) estimou que 1,35 milhões de pessoas morreram em acidentes de trânsito pelo mundo, sendo esta a oitava maior causa de mortes no mundo e a primeira responsável por mortes de pessoas nas faixas etárias de 5 a 29 anos, acontecendo três vezes mais em países em desenvolvimento do que em países considerados desenvolvidos [11]. O Brasil se configura como o quinto país com mais mortes por acidentes de trânsito, ficando atrás da Índia, China, EUA e Rússia [12].

A OMS estimou que, nesse ano (2018), somente na América, morreram 154.997 pessoas em acidentes de trânsito e só no Brasil foram 41.007, atingindo um índice de 19,7 mortes a cada 100 mil pessoas. Na América inteira esse índice é de 15,6 e no continente africano é de 26,6, configurando-se como a região da OMS que mais mata no trânsito, como é possível ver no gráfico da Figura 4. Isso evidencia outro resultado obtido pelo Global Status Report on Road Safety 2018, que indica que regiões menos desenvolvidas possuem maiores índices de mortes no trânsito.

É também nesses países que se possuem menores númerosde legislações de que cobrem os padrões chave de veículos adotados pela OMS, a fim de aumentar a segurança veicular, como o ESC, ABS para motociclistas, proteção padrão parar pedestres etc. Quase todos os países da África (com exceção de Egito e África do Sul), do Oriente Médio e alguns países da América do Sul possuem zero desses padrões aplicados. O Brasil possui 5 dos 8 considerados pelo órgão.

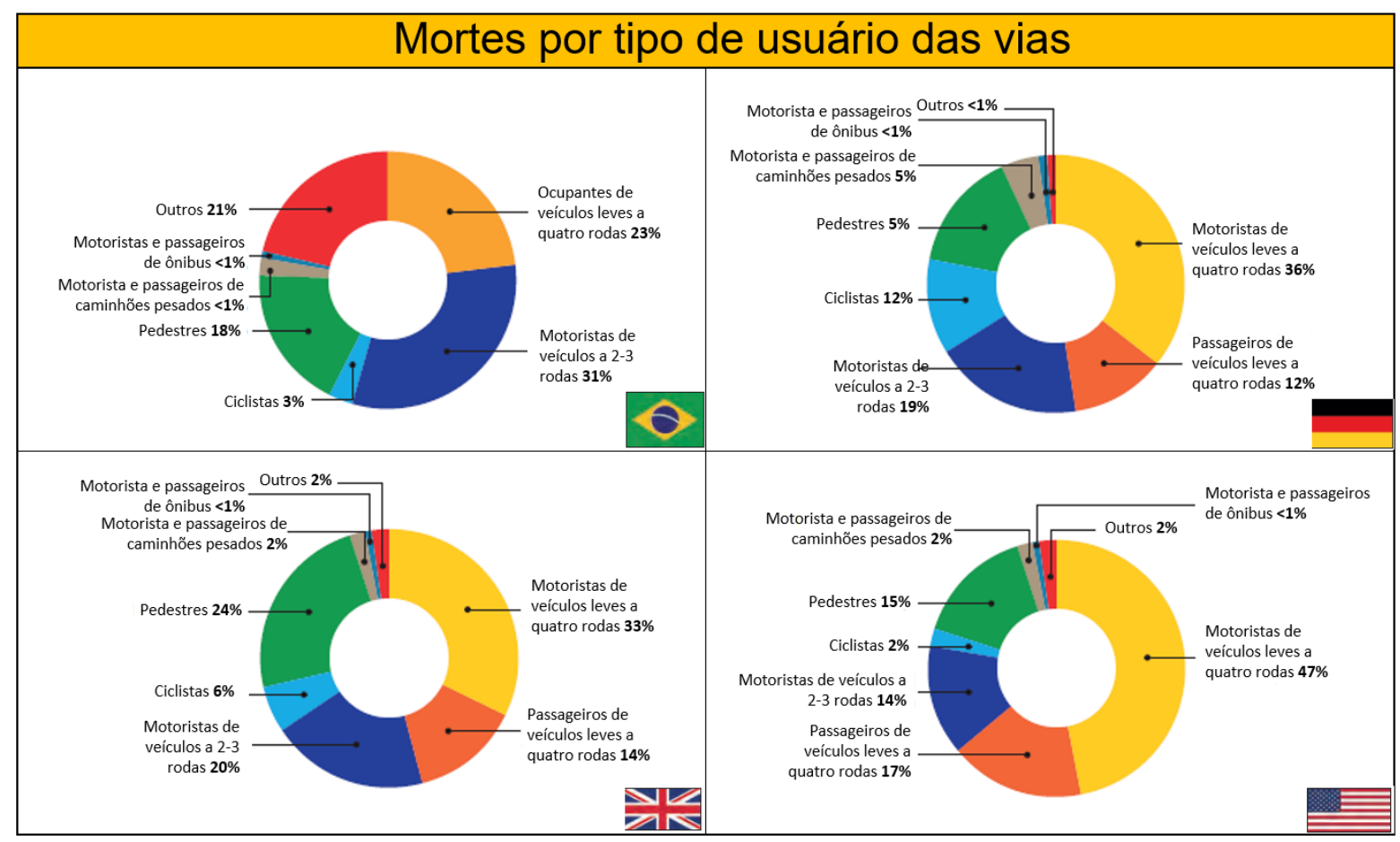

Figura 5- Quadro comparativo entre as mortes por categoria de usuário das vias na Europa, Estados Unidos e no Brasil. Fontes [11].

Com base nessas informações, pode-se iniciar algumas comparações das características de acidentes de trânsito na União Europeia e nos Estados Unidos, e encontrar algumas similaridades e diferenças em relação ao cenário brasileiro, a fim de entender quais tecnologias 
de assistência de direção poderiam ser aplicadas no país e se seriam necessárias algumas alterações.

Assim, na Figura 5, compara-se as mortes por categoria de usuário das vias em dois países da União Europeia (em 2018) e dos Estados Unidos com o Brasil. Vê-se que a proporção de pedestres vítimas de acidentes de trânsito possui a mesma ordem de grandeza em todos os casos, porém é possível ver que no Brasil existem muito mais acidentes envolvendo motociclistas que nas outras localidades, em que a maioria das mortes em acidentes de trânsito envolvem motoristas e ocupantes de veículos com 4 rodas. Além disso, a Alemanha possui uma peculiaridade de possuir uma alta taxa de acidentes com morte envolvendo ciclistas.

Dessa forma, pode-se dizer que em relação a acidentes envolvendo pedestres, proporcionalmente o Brasil se assemelha com esses países, mas a parcela de acidentes envolvendo veículos leves de 4 rodas é muito maior na Alemanha, Estados Unidos e Reino Unido, enquanto no Brasil, acidentes com veículos de 2 ou 3 rodas ocupam uma parcela maior.
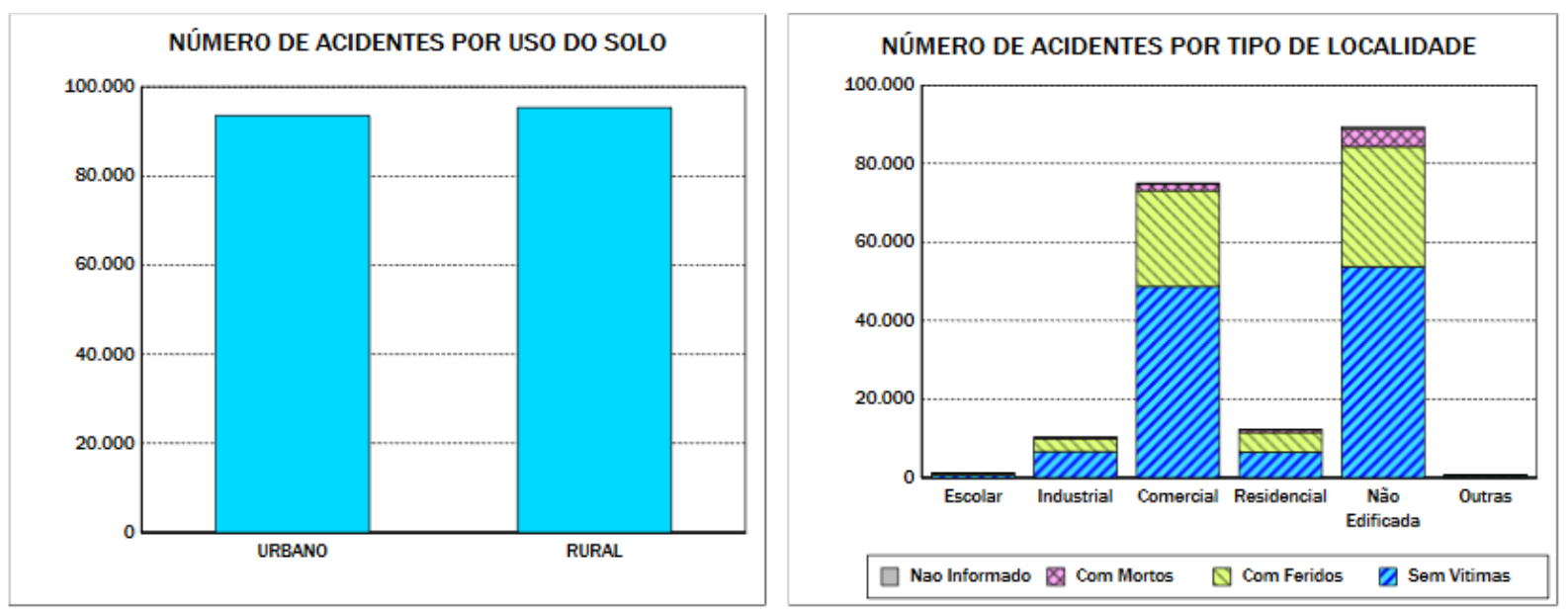

Figura 6 - Número de acidentes por uso do solo e por tipo de localidade no Brasil em 2011. Fonte [23].

Além disso, na Europa, 38\% dos acidentes ocorrem em área urbana e 62\% em zonas rurais (considerando autoestradas como zonas rurais) [13]. Já no Brasil, existe uma divisão um pouco mais igualitária dos acidentes quando separados dessa forma, como é mostrado na Figura 6. Além disso, pode-se dividir os acidentes por tipo de localidade, sendo locais não edificados onde aconteceram mais acidentes no Brasil no ano de 2011.

Ainda, ao avaliar a situação de países participantes da União Europeia e o Estados Unidos, reparou-se que existe uma forte preocupação com falta de atenção nas estradas, assim como no Brasil. Um estudo da NHTSA [13] mostra que em 2017, dos 34.247 acidentes fatais de trânsito, $9 \%$ foram causadas por falta de atenção no trânsito nos Estados Unidos. Mais dados podem ser visualizados na tabela da Figura 7.

\begin{tabular}{|c|c|c|c|}
\hline & Acidentes & Motoristas & Fatalidades \\
\hline Total & 34,247 & 52,274 & 37,133 \\
\hline Afetados por distração (A-D) & $\begin{array}{c}2.935 \\
\text { (9\% de todos os acidentes) }\end{array}$ & $\begin{array}{c}2.994 \\
\text { (6\% de todos os motoristas) }\end{array}$ & $\begin{array}{c}3.166 \\
\text { (9\% de todas as fatalidades) }\end{array}$ \\
\hline
\end{tabular}

Figura 7 - Tabela de colisões fatais, número de motoristas em colisões e fatalidades nos Estados Unidos em 2017. Fonte [13]. 
No Global Status Report on Road Safety, da OMS [11], também é mostrado a tendência de fatalidades em acidentes nas estradas entre os anos de 2007 a 2016. No Brasil, o número de mortes a cada 100.000 habitantes (Figura 8) aumentou ao longo dos anos e em países desenvolvidos esse número diminuiu. Naturalmente, esse parâmetro depende de muitos fatores, como legislações vigentes em relação à fiscalização da infraestrutura e do uso das vias e do nível socioeconômico do país. Mas é possível apontar pelo menos um denominador comum em países que obtiveram sucesso em reduzir a taxa de mortes em acidentes de trânsito que é a implementação de todos os padrões da UNECE (mais detalhes no Capítulo 3) para veículos mais seguros, como a presença do ESC, proteção para pedestre, ABS para motos e proteção de impacto frontal. O que se vê no Brasil é a presença recente de parte desses padrões (ABS, ABS para motos e proteção de impacto frontal), e uma tendência a incorporar, obrigatória e paulatinamente, tecnologias que aumentem a segurança veicular, a fim de seguir a tendência desses países, evidenciado por programas como o Rota 2030, de maneira nacional, estimulados pelas novas pontuações da Latin NCAP e pelo roadmap do DENATRAN.

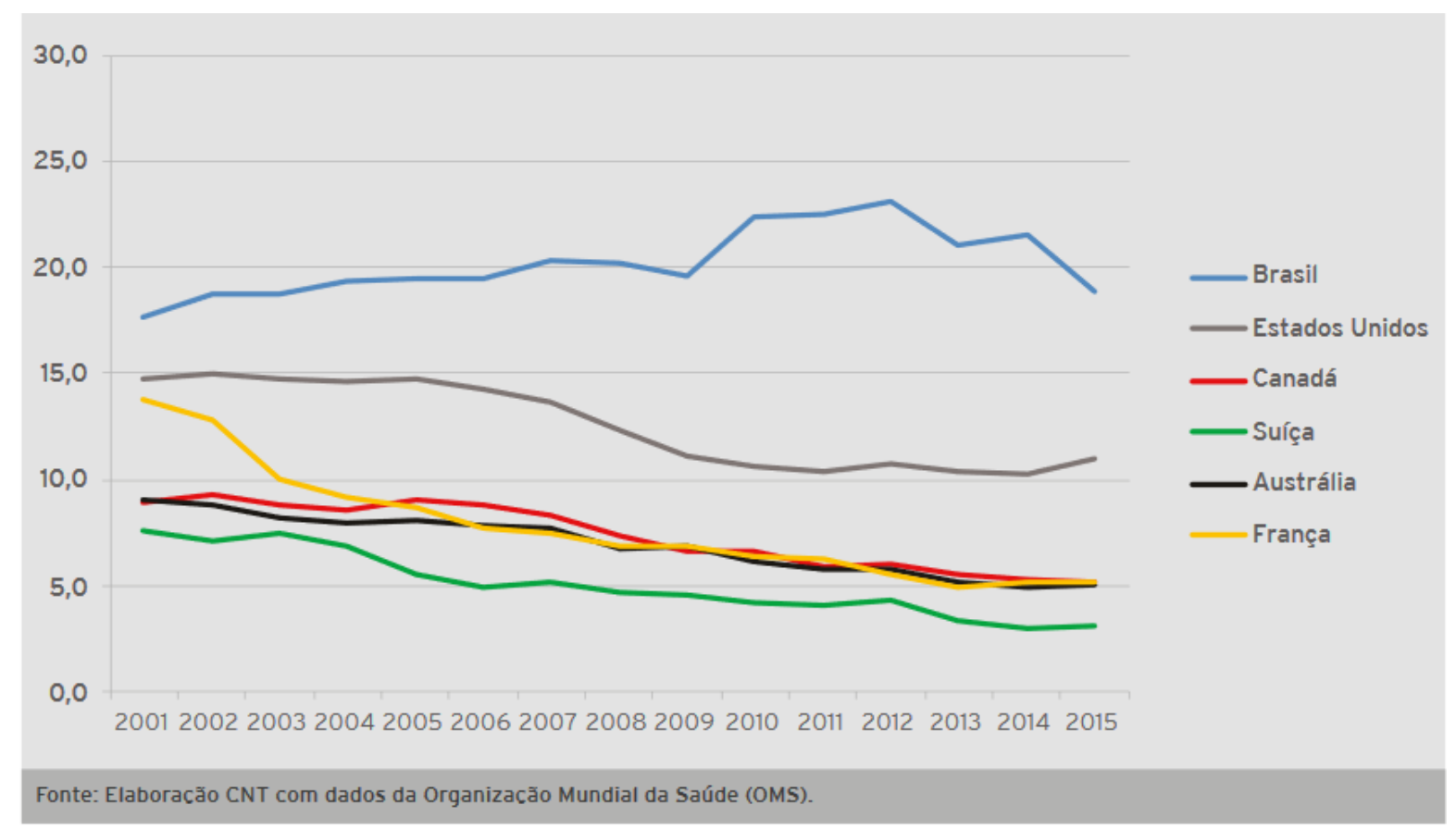

Figura 8 - Comparação entre as tendências do número de mortes a cada 100.000 no Brasil e em países desenvolvidos entre os anos de 2001 a 2015. Fonte [25].

\section{SEGURANÇA VEICULAR}

Equipamentos de segurança veicular como ESC (Controle de estabilidade eletrônico) e sistemas avançados de freio contribuem substancialmente para a redução de mortes e lesões em acidentes de trânsito. Apesar desses benefícios nem todos os novos veículos são obrigados a possuírem esses sistemas instalados. Mesmo assim, NCAPs foram efetivos em aumentar os níveis de segurança veicular em relação aos mínimos requerimentos regulatórios [11]. 
Atualmente 40 países implementam de 7 a 8 dos padrões de segurança veícular prioritários da UN (Nações Unidas), e 124 implementam de 0 a 1 . O Brasil está na lista dos que aplicam de 2 a 6 desses padrões, que são:

1. Proteção contra impactos frontais e laterais (R94 \& R95).

2. ESC (R140): Previne derrapagem e perda de controle em casos de oversteering e understeering. Também ajuda em prevenção de capotagem e em desvios abruptos.

3. Proteção dianteira para pedestres (R127). Modifica a parte diantera dos veículos, promovendo a utilização de bumpers "macios" que possam reduzir a severidade dos danos em um pedestre atingido por um carro.

4. Cinto de segurança e sua ancoragem (R14 \& R16). Certifica que os cintos são montados no veículo ainda na linha de produção e que a sua ancoragem é o suficiente para aguentar o impacto durante um acidente.

5. Segurança da criança. Visa garantir que a cadeira da criança está no local correto para o cinto de segurança e que a ancoragem de restrição para crianças ISOFIX está nos conformes.

6. ABS (Anti-Lock brake system) para motos. Ajuda o motorista a manter o controle durante uma frenagem de emergência.

Além disso, sistemas de segurança veicular se dividem entre ativos e passivos. Sistemas passivos atuam durante acidente, tentando mitigar os danos causados aos ocupantes do veículo. $\mathrm{O}$ airbag e o cinto de segurança são exemplos desse tipo de sistema. Por sua vez, os ativos atuam na prevenção de um possível acidente, como é o caso do sistema de controle de estabilidade (ESC), que atua no sistema de freio para garantir a estabilidade e a dirigibilidade de um veículo durante a frenagem e outras situações de risco, como underloversteering ou desvios abruptos.

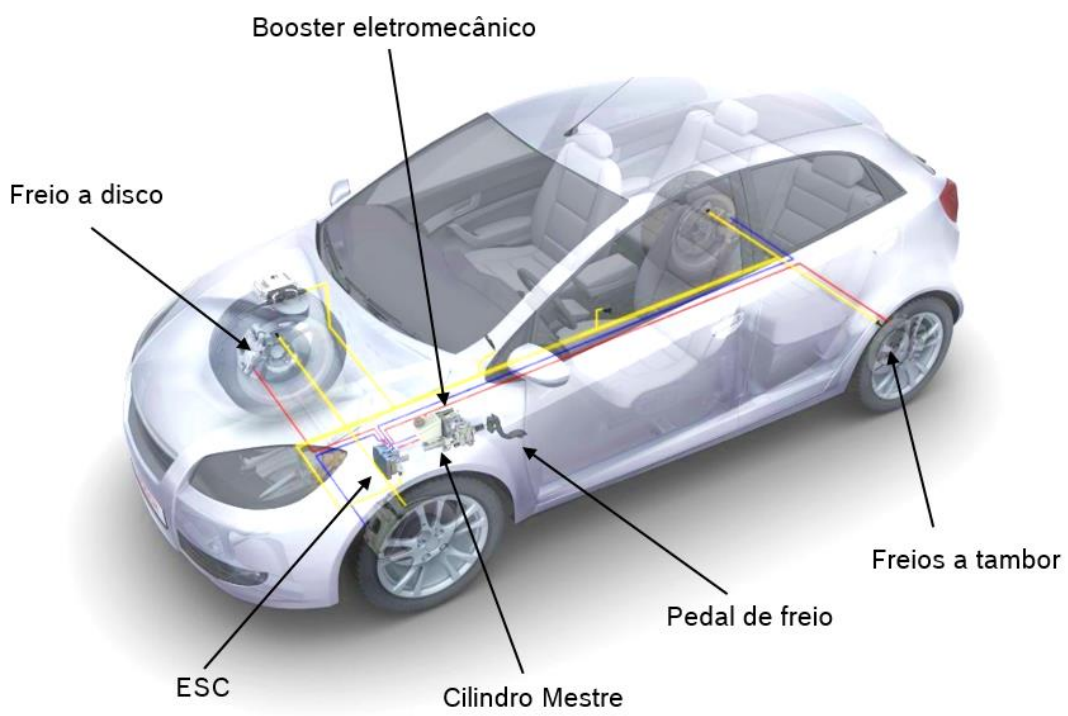

Figura 9 - Novos sistemas de freios.

Atualmente, o sistema de freio é essencial em segurança veicular ativa, já que é mais provável de se evitar ou reduzir os danos de um acidente ao reduzir a sua velocidade. A Figura 9 representa um novo tipo de sistema de freio. Como já fora citado, existia apenas o ABS, como 
modulador da pressão do fluido de freio, que visa evitar o travamento das rodas durante a frenagem. No lugar dele agora existe o ESC, que além de realizar a modulação, implementa funções de controle de tração e da dinâmica do veículo, aumentando a segurança veicular em situações mais críticas, como diferença de atritos entre as rodas do veículo, ou uma manobra abrupta de desvio. O ESC, aliado com sistemas de assistência de direção, como radares ou câmeras, também consegue executar frenagens autonômas de emergência.

Uma vez que os motores estão cada vez mais eficientes, e dada uma tendência à eletrificação dos veículos, é necessário a utilização de uma bomba de vácuo para que um booster convencional funcione. Assim, boosters eletromecânicos (iBoosters) podem ser uma opção, uma vez que a amplificação da força de frenagem é realizada por um motor elétrico. Além disso, iBoosters podem estabelecer novas funções junto com o ESC, garantindo redundância no sistema freio e maior segurança, uma vez que, devido a sua dinâmica superior, são capazes de aumentar a pressão mais rapidamente. E ainda aumentam o potencial de frenagem regenerativa em veículos híbridos ou elétricos, quando trabalham de forma cooperativa com o ESC.

O resto do sistema, por enquanto, se mantém o mesmo, com a pressão sendo gerada dentro do cilindro mestre e transmitida, de forma modular (para os freios de roda). Em veículos elétricos ou híbridos (HEV), há uma segunda forma de frear o carro que é utilizando o próprio motor do carro como freio motor. Devido às limitações na capacidade de frenagem da máquina elétrica, em determinadas situações, existe uma combinação entre frenagem hidraúlica e elétrica em veículos HEV, executada pelo ESC e, se presente no sistema, pelo iBooster.

\subsection{ADAS}

Várias situações críticas no trânsito exigem uma ação rápida sem perder de vista o tráfego a frente em cada instante de tempo. Os sistemas avançados de assistência ao motorista (do inglês Advanced Driver Assistance Systems - ADAS) ajudam os motoristas a chegarem seguros e relaxados no seu destino. Esses sistemas atuam como copilotos eletrônicos, tornando o tráfego rodoviário mais seguro e são uma parte essencial da ideia da condução livre de acidentes [14].

A finalidade do ADAS é reduzir ou até eliminar o fator erro humano do trânsito. Os benefícios das implementações ADAS são notáveis devido a uma diminuição significativa na redução de acidentes, custo econômico e poluição [15].

O ADAS pode detectar objetos, fazer uma classificação básica, alertar o condutor para situações perigosas na estrada e, em alguns casos, desacelerar ou parar o veículo. Estes níveis de recursos do ADAS se encaixam em aplicações como frenagem automática de emergência, monitoramento de ponto cego, assistente de manutenção de faixas e aviso de colisão dianteira [16].

\subsection{AEB}

As funções de frenagem automática de emergência (do inglês Automatic Emergency Braking - AEB) foram desenvolvidas para reduzir o número ou as consequências de colisões traseira. Quando a função AEB detecta que a distância do veículo à frente no 
trânsito é criticamente curta, alerta o motorista para o risco de uma colisão e prepara o sistema de frenagem. Caso o motorista não demonstre reação a situação crítica, AEB pode iniciar a frenagem completa para evitar a colisão ou parcial para minimizar as consequências da colisão. Dependendo do escopo e da área de uso, as funções de AEB podem ser divididas de maneira geral em: AEB City, AEB Inter-Urban e AEB Vulnerable Road Users (VRU) [17].

As colisões traseiras estão entre os piores tipos de acidentes de trânsito, principalmente se pedestres ou ciclistas estiverem envolvidos. O AEB VRU pode impedir totalmente estes tipos de colisões ou atenuar consideravelmente seu impacto. Dessa forma, este tipo de função pode reduzir substancialmente o risco de lesões para pedestres ou ciclistas. Para o AEB City e do AEB Inter-Urban, o objetivo é evitar colisão traseira entre dois veículos, diferindo apenas quanto a velocidade e a área de atuação. O AEB City opera em baixas velocidades dentro das cidades, enquanto que o AEB Inter-Urban opera para altas velocidades fora do perímetro urbano [18].

Para se realizar a função AEB é necessário a câmera frontal e/ou o radar junto ao ESC (Electronic Stability Control), sendo este último necessário para a atuação do freio. $\mathrm{O}$ radar e a câmera conseguem realizar o data fusion para aumentar a confiabilidade e garantir redundância, permitindo um sistema mais seguro. Estes três dispositivos trabalham em conjunto para executar o AEB: a câmera visualiza o seu target (formato, cores, distância, etc), o radar faz a confirmação destas informações, pois em caso de situações em que o clima dificulte a visibilidade - como neblina, névoa ou chuva - a câmera não terá um grau de confiabilidade alto para confirmar tal informação, e, portanto, o radar atuará para calcular a velocidade e distância do target; por fim, temse o módulo de frenagem ESC que realiza a desaceleração do veículo afim de evitar a colisão.

Para tanto, o ESC recebe uma informação de desaceleração do sistema redundante radar-câmera. Em sistemas que possuem um booster a vácuo, o ESC é responsável por, de forma autonôma, aumentar a pressão do fluido de freio, para desacelear o veículo. Caso o veículo possua um iBooster, o ESC deverá enviar um valor de fluxo de volume de fluido para o servo freio, que por sua vez irá ser responsável pela atuação da frenagem, com uma dinâmica maior. Caso o booster eletromecânico apresente alguma falha, ou não consiga executar por completo a frenagem solicitada o ESC consegue compensar o que falta para garantir a frenagem [19].

\section{MERCADO}

É válido entender a movimentação do mercado em torno de funções de assistência de direção, para avaliar se de fato há uma tendência a implementação dessas tecnologias, influenciadas por programas ou legislações que visam aumentar a segurança veicular. Isso ajuda a fortalecer a visão de que programas como Rota 2030 e o sistema de avaliação NCAP podem acelerar a aplicação dessas tecnologias no Brasil.

A Comissão Europeia (do inglês, European Commission - EC) publicou um regulamento em julho de 2009 que torna obrigatória a presença de sistemas de Aviso de Saída de Faixa (do inglês Lane Departure Warning - LDW) e Frenagem Automática de Emergência nos veículos 
pesados. Este regulamento entrou em vigor em novembro de 2015. Nesta data, todos os novos veículos com a capacidade de transportar mais de oito passageiros ou mais de 3,5 toneladas de mercadorias deveriam estar equipados com estes sistemas [20].

Em maio de 2018, A EC propôs que todos os veículos novos introduzidos no mercado europeu a partir de 2021 tenham onze funções ADAS, como: frenagem automática de emergência, assistente de manutenção de faixa, reconhecimento de distração do motorista, entre outras. Com essa proposta, a EC espera que 7.300 vidas sejam salvas e que 38.900 ferimentos graves sejam evitados no período de 2020 até 2030.

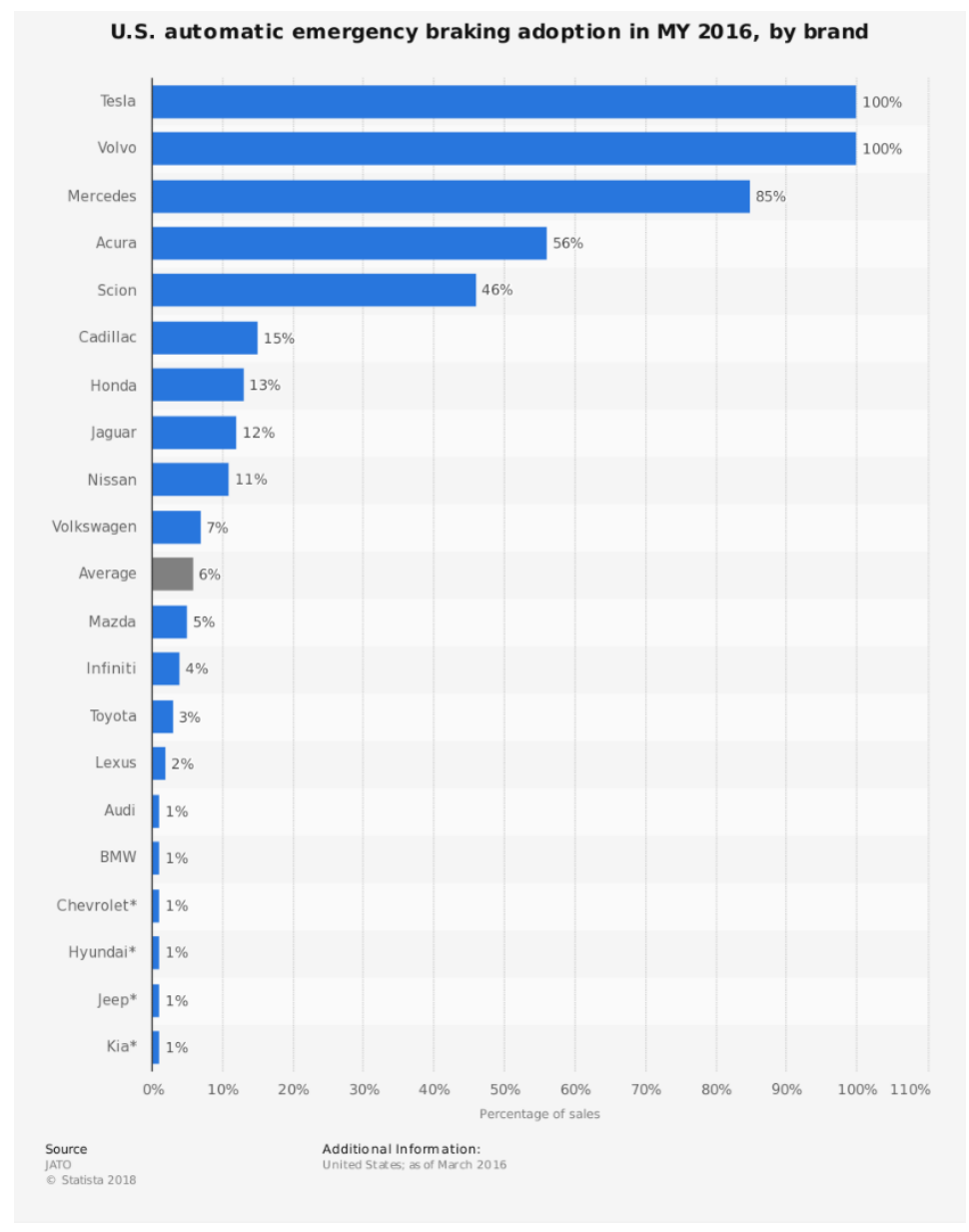

Figura 10 - Adoção do Sistema autônomo de frenagem por marcas nos EUA. Fonte [27].

Nos EUA, the National Highway Traffic Safety Administration (NHTSA) e o Insurance Institute for Highway Safety (IIHS) anunciaram um compromisso entre vinte montadoras de automóveis que representam $99 \%$ do mercado automotivo americano. Este acordo teve como finalidade tornar o AEB um item padrão em praticamente todos os veículos novos a partir de setembro de 2022. A IIHS estima que este compromisso irá prevenir até 28.000 acidentes e 12.000 lesões por volta de 2025.

No Brasil, no ano de 2017 cerca de 1\% dos veículos possuíam AEB de série, e também existem outros $1 \%$ que foram vendidos como um opcional para diferentes versões dos veículos. De forma direta, cerca de 12.000 veículos foram vendidos com AEB em 2017. Já na Alemanha, no ano de 2016, 32\% dos novos carros da Alemanha possuíam o sistema. Já nos Estado Unidos, 
100\% da frota dos veículos da Tesla e da Volvo possuem AEB, como é possível verificar na Figura 10.

No gráfico da Figura 11, pode-se perceber alguns detalhes importantes em relação ao mercado. Em relação aos carros de passageiros (carros leves), tem-se um equilíbrio muito grande entre as regiões em relação a oferta do AEB. Existe um pequeno destaque para a Europa com 59\%, não sendo nada expressivo em relação as outras regiões. Para a categoria de utilitários e minivans destaca-se a Europa, com cerca de $85 \%$ dessa categoria sendo ofertada. Outro dado que chama a atenção é para Vans e Caminhões nos EUA, onde existe um percentual muito baixo, cerca de 3\%, talvez isso possa ser um indicativo de desinteresse por parte dos americanos.

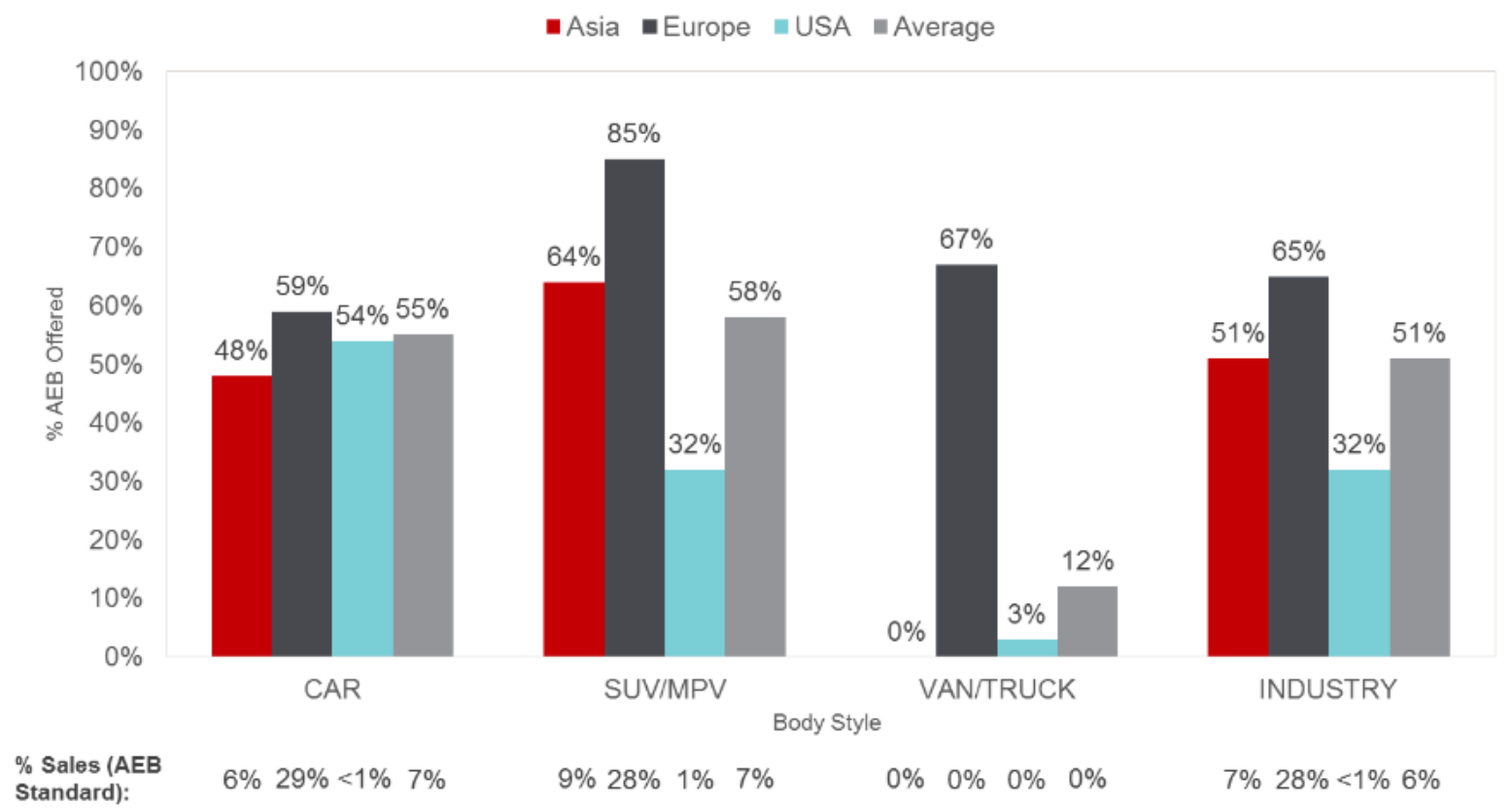

Figura 11 - Comparação dos mercados de AEB por tipo de veículo na Ásia, na Europa e nos EUA. Fonte [28].

\section{CONCLUSÃO}

Encontrar alguma intersecção entre os cenários brasileiro e de outros países que justificasse a implementação de tecnologias de segurança veicular, com foco no AEB, na frota brasileira era o objetivo da análise.

Assim, as análises mostram semelhanças já esperadas, como a proporção de pedestres envolvidos em acidentes e a preocupação com a distração dos motoristas. Um fato inesperado foi a semelhança entre as localidades desses acidentes, sendo, no Brasil e na Europa, predominantemente na zona rural (tido por rodovias). Esperava-se que zonas urbanas compreendessem um número maior de acidentes, principalmente na Europa.

Discrepâncias foram reconhecidas na proporção das categorias de usuário das vias envolvidos em acidentes também. No Brasil, esta proporção é alta para motociclistas, enquanto que nos Estados Unidos e países da Europa acidentes envolvendo veículos leves de quatro rodas são 
predominantes, o que aponta uma particularidade do trânsito brasileiro em relação a esses países. Isso acontece por que, em algumas regiões do país, como o nordeste por exemplo, a frota de motocicletas é maior que a de carros. Em 2018, em 45\% das cidades brasileiras, o número de motos já era maior que o de carros [21].

Esses dados apontam para a utilização de tecnologias de assistência de direção específicas. Por exemplo, seria interessante que fosse possível a detecção de um motociclista ou pedestre para a execução de uma frenagem autônoma de emergência, no Brasil, não considerando apenas veículos leves e pesados de quatro rodas, que também devem ser detecados, principalmente em zonas rurais, em que a velocidade do veículo é maior.

Sendo assim, faz sentido o Programa Rota 2030, o roadmap do DENATRAN e o Latin NCAP influenciarem na implementação desse tipo de sistema, uma vez que algumas características de países da Europa e dos Estados Unidos se repetem aqui, e ainda percebe-se algumas particularidades. Além disso, o Brasil também enfrenta um alto índice de acidentes a cada 100 mil habitantes, um grande fator motivacional para encontrar qualquer solução que diminua esse índice.

O Programa Rota 2030 vem em forma de incentivos fiscais, uma vez que a implementação de novas tecnologias não é necessariamente atraente ao mercado devido ao seu alto custo. Essas tecnologias precisam atingir uma grande parte da população para que seus resultados sejam visíveis e efetivos. Sendo assim faz sentido esse tipo de incentivo as montadoras que seguirem os planos estabelecidos no programa, o que abre a porta desse mercado aqui no Brasil para os fornecedores desse tipo de sistema.

Enquanto o Rota 2030 incentiva monetariamente, o roadmap do DENATRAN, projeta para o futuro uma obrigatoriedade de alguns equipamentos e funções de segurança veicular, já sinalizando para os produtores de automóveis a necessidade de implementar esses itens. Sendo assim, os dois caminham lado a lado, uma vez que as montadoras que estiverem de acordo com os planos do programa, se prepararão para o futuro, evitando custos adicionais da implementação desses itens.

Por sua vez o Latin NCAP, serve como um instumento de divulgação e Marketing, que, além de realmente atestar o nível de segurança do veículo, é parâmetro de comparação para o consumidor final do carro, no momento da aquisição. Geralmente é preferível adquirir um carro que possui uma boa performance nos testes realizados pelo NCAP, que, devido aos incentivos fiscais, poderão ter preços mais acessíveis no futuro.

Em relação ao mercado mundial, pode-se reparar que a implementação do AEB já é uma tendência e é liderada, nos Estados Unidos, pela Tesla e pela Volvo, que possuem esse sistema em $100 \%$ da frota no país. Europa e Ásia também já vão nessa direção, mostrando que esse é um item de segurança veicular que pode se tornar essencial no futuro (Figura 11). Além disso, o crescimento desse mercado foi definitavemente impulsionado por legislações e programas que tem como objetivo melhorar a segurança veicular nesses países. Os efeitos das aplicações dessas medidas, que não envolvem apenas a embarcação de novas tecnologias nos carros, mas também investimento em infraestrutura e educação, podem ser visualizados na Figura 8 , em que o índice de mortos em acidentes de trânsito a cada 100.000 habitantes reduziu no período de 2001 a 2015 nos Estados Unidos e em alguns países da Europa, objetos de estudo e comparação com o cenário brasileiro neste artigo. 


\section{REFERÊNCIAS}

[1] BRASIL, “LEI No 13.755, DE 10 DE DEZEMBRO DE 2018," Diário Oficial da União, 11 dez. 2018 Seção 1, p.21, 2018.

[2] L. Felix, E. A. Brito e V. Matsubara, “O que é o "Rota 2030"," Uol, 2018. [Online]. Available: https://www.uol/carros/especiais/rota-2030-o-que-muda-no-carro-dobrasil.htm\#o-que-e-o-rota-2030. [Acesso em 21 Maio 2019].

[3] EURO NCAP, "How to read the stars," [Online]. Available: https://www.euroncap.com/en/about-euro-ncap/how-to-read-the-stars/. [Acesso em 21 Maio 2019].

[4] EURO NCAP, "The car selection explained," [Online]. Available: https://www.euroncap.com/en/about-euro-ncap/the-car-selection-explained/. [Acesso em 21 Maio 2019].

[5] "Salvar VIDAS - Pacote de medidas técnicas para a segurança no trânsito.," Organização Pan-Americana da Saúde, Brasília, DF:, 2018.

[6] Vision Zero Network, "What is Vision Zero?," [Online]. Available: https://visionzeronetwork.org/about/what-is-vision-zero/. [Acesso em 21 Maio 2019].

[7] P. Pacheco, "Visão Zero: é possível zerar as mortes no trânsito," The City Fix Brasil, [Online]. Available: http://thecityfixbrasil.com/2017/01/09/visao-zero-e-possivel-zeraras-mortes-no-transito/. [Acesso em 21 Maio 2019].

[8] NYC, "Vision Zero," NYC: The Official Website of the City of New York, [Online]. Available: https://www1.nyc.gov/site/visionzero/index.page. [Acesso em 21 Maio 2019].

[9] DNIT, "Estatísticas de Acidentes: Quadro 0101 - Número de Acidentes por Gravidade," 0712 2009. [Online]. Available: https://189.9.128.64/download/rodovias/operacoesrodoviarias/estatisticas-de-acidentes/quadro-0101-numerodeacidentesporgravidadeanode2011.pdf. [Acesso em 2005 2019].

[10] P. e. A. C. Ministério dos Transportes, "Avaliação das Políticas Públicas de Transportes - Segurança nas Rodovias Federais".

[11] World Health Organization, "Global Status Report on Road Safety 2018," Geneva, 2018.

[12] Jornal do Senado, "Estudo da Organização Mundial da Saúde (OMS) sobre mortes por acidentes de trânsito em 178 países é base para década de ações para segurança," Senado, [Online]. Available: http://www.senado.gov.br/noticias/Jornal/emdiscussao/motos/saude/estudo-daorganizacao-mundial-da-saude-oms-sobre-mortes-por-acidentes-de-transito-em-178paises-e-base-para-decada-de-acoes-para-seguranca.aspx. [Acesso em 2005 2019].

[13] NHTSA, "Distracted Driving Fatal Crashes," 2017.

[14] Continental, “ADAS - Advanced Driver Assistance Systems," [Online]. Available: https://www.conti-engineering.com/CMSPages/GetFile.aspx?guid=cf6d6925-814846e9-b59a-6eed8c23a0f6. [Acesso em 2004 2019].

[15] K. A. J. W. H. W. D. Brookhuis, "Behavioural impacts of Advanced Driver Assistance Systems-an overview," European Journal of Transport and Infrastructure Research, vol. 3, pp. 245-253, 2001. 
[16] NVIDIA, “Advanced Driver Assistance Systems (ADAS),” [Online]. Available: https://www.nvidia.com/en-us/self-driving-cars/adas/. [Acesso em 2005 2019].

[17] Bosch, "Predictive Emergency Braking Systems," [Online]. Available: https://www.bosch-mobility-solutions.com/en/products-and-services/passenger-carsand-light-commercial-vehicles/driver-assistance-systems/predictive-emergency-brakingsystem/. [Acesso em 2005 2019].

[18] Bosch, "Predictive Pedestrian Protection," [Online]. Available: https://www.boschmobility-solutions.com/en/products-and-services/passenger-cars-and-light-commercialvehicles/driver-assistance-systems/predictive-pedestrian-protection/. [Acesso em 2005 2019].

[19] VDA - Verband Der Automobilindustrie, "Recommendation for the implementation of a Communication Interface between an Electrical Brake Booster and an ESC Control Unit," 2016.

[20] Automotive, "Compulsory ADAS for European trucks set to expand," Automotive, [Online]. Available: https://www.tu-auto.com/compulsory-adas-for-european-trucks-setto-expand/. [Acesso em 22 Maio 2019].

[21] D. Brito, "Número de motos é maior que o de carros em $45 \%$ das cidades," EBC Agência Brasil, [Online]. Available: http://agenciabrasil.ebc.com.br/geral/noticia/201807/numero-de-motos-e-maior-que-o-de-carros-em-45-das-cidades. [Acesso em 22 Maio 2019].

[22] NHTSA, "Driver Assistance Technologies," [Online]. Available: https://www.nhtsa.gov/equipment/driver-assistance-technologies. [Acesso em 2005 2019].

[23] DNIT, "Estatísticas de Acidentes: Quadro 0107 - Número de Acidentes por Uso do Solo e Tipo de Localidade," [Online]. Available: https://189.9.128.64/download/rodovias/operacoes-rodoviarias/estatisticas-deacidentes/quadro-0107-numero-de-acidentes-por-uso-do-solo-e-tipo-de-localidade-anode-2011.pdf. [Acesso em 1804 2019].

[24] E. Comission, “Annual Accident Report," 2018.

[25] CNT, “Acidentes Rodoviários e Infraestrutura,” Brasília, 2018.

[26] Global NCAP, “About Global NCAP,” [Online]. Available: http://www.globalncap.org/about/. [Acesso em 21 Maio 2019].

[27] "U.S. automatic emergency braking adoption in MY 2016, by brand," statista, march 2016. [Online]. Available: https://www.statista.com/statistics/690691/us-automaticemergency-braking-adoption/. [Acesso em 23 Maio 2019].

[28] JATO, "U.S MARKET INSIGHTS. AUTOMATIC EMERGENCY BRAKING (AEB)," June, 2016. 